\title{
Emplacing the Culture of Transparency and Accountability in Tertiary Institutions in Nigeria for Development ${ }^{1}$
}

\author{
'Femi Odekunle
}

\section{Introduction}

I feel honoured and priviledged to deliver the Keynote Address to this august gathering on transpenrency/accountability in our tertiary institutions. I am at home on the two subjects of tertiary education and corruption in Nigeria because I have been an active "actor" in our university-system since 1965, playing various roles over the period - from student to lecturer, Departmental Head to Faculty Dean, statutory membership of senate to elected/appointed membership of Governing Councils of three universities and Chairmanship of the Standing Committee of the Board of National Universities Commission on Quality Assurance, along with the "derivatives" of those roles (Odekunle,1980). Moreover, the subject of corruption has been my major and enduring intellectual and public-policy concern from the very early eightes to date (e.g. Odekunle, 1983;2012a ;2012"; $2012^{\mathrm{C}}$ ).

The role of tertiary education in national and sustianable development cannot be over emphasized (Mkpa and Gurin,2011:335-371). To the extent that Nigeria is growing but remains essentially underdeveloped, in the context of the appropriate conceptualization of the concept of "development" the place of tertiary education in the matter ought to be examined (Abangma,2011:127-148). And in examining that "place", certian questions arise: the extent to which responsible state and national authorities enable the institutions to play their mandated/ expected role; the extent to which the institutions are "self-disabling" with respect to effective and efficient performance in their roles; the factors responsible for any observed deficits in the performance of their role for the optimal realization of our desired development; and possible anti-dotes to such identified disabling factors.

In discussing these and related issues, the next section reiterates the importance of tertiary education to national development while the third section briefly highlights the state of tertiary education in the country and accounts for the situation, with emphasis on the corruption factor. The fourth section offers suggestions for the optimal emplacement of transparency and accountability in our tertiary institutions. Finally, I shall in the fifth and final section conclude that the wider societal context must, pre-requsitively, be enabling to such an emplacment in our tertiary institutions.

\section{Importance of Tertiary Education to National Development}

"Development" means the continous improvement in the quality of life and existence and which improvement is increasingly evenly distributed among the overwhelming majority of the population (Odekunle,2012 $\mathrm{c}: 8-12$ ). There is also the element of sustainability whereby the continuous improvement and its increasenly-even distribution can be maintained, upheld 
and nourished over an appreciable period of time. And it is anchored on commonly-Shared ethical values of fairness, equity, justice and to which succeeding leaderships are committed.

This understanding of development provides an appropriate and the required connection between what sociologists call material culture (i.e. growth) and "non-material culture" (i.e. the ethical application/consumption of the proceeds of the growth). Thus, even though they are related, "development" should not be equated or confused with "growth" which is essentially a summation of physical infrastructures, GDP, stock-exchange/market activities, foriegn reserves and the like of these. Indeed, evidence abound that there can be growth without development.

To achieve/realize "development", society is variously organized into sectors among which the "education sector" is most primary and virtually generic. Hence, for Nigeria, the enduring purpose of education as enumerated in a 1977 Government White Paper includes : the inculcation of national consciousness and national unity; the inculcation of the right type of values and attitudes for the survival of the Nigerian society; the training of the mind in the understanding both the immediate and the remote world; and the acquisition of appropriate skills, abilities, and competences, both mental and physical, as equipment for the individual to live in, and contribute to, the development of society.

It is important to say that the "higher-education" institutions have the most influence, compared to the lower primary and secondary levels, in terms of stature and intellectual resources in the determination of the character, direction and emphasis of programmes and instruction as well as in the production of personnel for the whole sector.

In summary, the importance of tertiary education to national and sustainable development inheres in its role in the production/application of knowledge for the betterment of society and the socioeconomic survival of its citizens; and in the related production of trained/ informed manpower for the development of society and the self fulfillment of the individuals so trained.

It is in this regard that it should be instructive that higher-education in the United States of America, for instance, has been credited with transforming the nature of the American economy through scientific and social research that has dramatically enhanced the country's "development" and improved the quality of life of her citizens. Higher education also contributes to good governance at the city, state and country levels with regard to the level of discourse and public debate about the country's socio-economic and political future. Finally, it helps to create an informed citizenry vital to a democratic society; ditto for Malaysia (NUC, 2011:76)

Of course, to play the role encapsulated in the last paragraph but one above and perform optimally as its counter-part in the USA and Malaysia, higher/tertiary education in Nigeria has to be enabled with the appropriate quantum and quality of institutions as well as with an enabling ethical environment that equally demands/extracts corporate social responsibility from the institutions. The what, how and why of the state and developmental-output of tertiary institutions in Nigeria today constitute the focus of the third section of this Address. 


\section{Accounting for the State of Tertiary Institutions the Corruption Factor}

For the purpose of tertiary education, Nigeria as at 2009 had a total of 357 tertiary institutions (FME, 2009:54) made up of 94 Universities, 115 Polytechnics/Monotechnics, 86 Colleges of Education, and 62 Innovative Enterprise Institutions. As of today according to figures obtained directly from JAMB, they are 463, made up 125 universities, 88 Polytechnics, 50 Monotechnics, 116 Colleges of Education, 73 innovative Enterprise Institutes, and 11 Special Tertiary.

The state of these institutions has been observed and assessed (FME, 2009:55-68; Abangma, 2011:127-148; NUC, 2011:14-40) over the issues of access, quality, relevance, cost, and governance. And on these criteria, taken together as an entity, the institutions have been found wanting.

The observed deficits are attributed to the combination or "interaction" of the following overtime:

- absence of adequate planning for their establishment, post - 1975: progressive deterioration of quality of prospective SSS products/ entrants;

- $\quad$ inadequate/obsolete/badly-maintained infrastructure and equipment and poor library facilities;

- $\quad$ gross under-funding relative to student population explosion;

- $\quad$ serious academic staff shortages, compounded by brain-drain;

- divided interests/moonlighting by academics, worsened by certain un-ethical practices by lecturers;

- $\quad$ examination malpractices and cultism-related insecurity on campuses; disruption/ instability of academic calendar due to incessant and prolonged strikes;

- outdated curricula that are hardly relevant to contemporary national development needs, let alone global competiveness;

- $\quad$ inadequate symbiotic relationship with industry or the organized private sector;

- weak, unethical and politicized leadership at Council and Management levels; and,

- lack of regular Management Audit exercise, or the implementation of its outcome, to ensure attainment of institutional goals.(Please, see Appendix)

However, while the attribution of the observed untoward state of our tertiary institutions to any of the foregoing factors (or their cumulated "interaction") cannot be faulted, most of the factors are themselves consequences of the dominant ethos which emerged in the country in the last half of the 1970s and became institutionalized by the mid-eighties: the elevation of "individual interest over and above "collective interest". And this subordination of the letter to the former is the causative-context of the demise of the erstwhile culture of integrity, transparency and accountability and, correspondingly, the intensification and intensification of the cancerous corollary: corruption.

Contrary to limiting the definition of a monetary term, it is indeed any act or deliberate omission, in the realm of public or corporate functioning, which gives illegitimate/or illegal benefit or advantage to the individual and to the detriment of the collective/public/corporate interest of the group, community or nation (Odekunle, 2008:3). The money-centred conception 
of corruption only "scratches", as it were, the tip of the iceberg because it blindfolds people from appreciating the more damaging fact and cost of other forms of corruption that are incidental, causal and/or consequential to the financial type. Such include the following:

- Policy/legalized corruption;

- Political/electoral corruption;

- Administrative/bureaucratic corruption;

- Professional/occupational corruption; and,

- Artisan/work-place/routine corruption.

The fact and the endemic prevalence of corruption in our society is not in doubt. And neither is its unquantifiable damage to and definitive untoward consequences for our economy and polity (in all conceivable respects) contestable. However, the overall cost burden of corruption is most manifest in the fact that even though the country continues to "grow" physically and materially and a tiny fraction of the population continues to be wealthier and wealthier via that growth, our "development" output is anything but the desirable economic and social objectives for the overwhelming majority of the population. Corruption is the "intervening variable" that prevents the translation of "growth" into "development".

It goes without saying that tertiary institutions (and the whole of the education sector) are part and parcel of the Nigerian society and, therefore, could not have remained immune from its dominant ethos nor "escaped" its consequences in terms corrupt practices and below-optimum sector-output. The introduction of the Babangida regime's infamous Structural Adjustment Programme (a.k.a. SAP), along with the incipient infusion of military dictatorship into the education sector, marked the "formal" but undeclared "entry" of corruption into tertiary institutions in the country.

This "external" environment, systemic and immediate, incubated the "internal" one in the institutions and resulted in the gradual but observable emergence of assorted un-ethical and outrightly corrupt practices in various important and peripheral loci in the institutions, via varying avenues; Governing Councils, ChiefExecutives, Registry Departments, Bursaries, Works/Maintenance, Faculties and Departments, Staff and Student Unions. And the avenues include appointment to leadership-position for various levels, contract conception/processing/ award, salary-bills, staff appointment/promotion, over-head expenditure, admission-exercise, examination-administration, award of grades for tests and examinations, accreditation-exercise, discipline of students and staff.

Extrapolated from what we know about the consequences of corruption on our polity (Odekunle 2008:4), the net-effect of the relative lack of transparency, accountability, and ethical values in our tertiary institutions includes the following:

- Loss of scarce institutional revenue on a systematic basis;

- Undermining of the sustenance of a culture of ethics and discipline among staff and students;

- Tainting of the quality-image of the institutions locally and abroad; 
- Creation of an environment of impunity and indiscipline in which un-acceptable proportions of staff and students believe that corruption pays if/when the perpetrator is "rightlyconnected"; and,

- $\quad$ Sabotage of effective enforcement of rules and regulations and the associated maintenance of the culture of rule of law and due-process in the institutions.

Again, just as the most debilitating overall effect of corruption on our polity is its "prevention" of the translation of "growth" into "development", so is the undermining of the actual and potential contribution of our tertiary institutions to national development the overall manifest dysfunction of the phenomenon of corruption therein. It should therefore be no wonder that our tertiary institutions are no longer able (unlike the period before the mid 1980s) to fulfill the role envisaged in the 1977 White Paper or contribute optimally to the development of the country as their counterparts in the USA or Malaysia. And our society can neither demand nor extract the envisaged "output" from them in spite of their "growth" in number and population, having failed to provide them the "enabling" monetary/material and, especially ethical, environment.

There is a need here to point out that my "brief, or bird's-eye view, on the state of our tertiary institutions does not mean they have not made any contributions whatsoever. The issue is about their role in "development" as conceptualized and as purposed in the 1977 White Paper. For instance Obafemi (2011:349 - 355) lists their "contribution" to include production of human-resource capital; increase in literacy rate; contributions to oil and gas sector, agricultural development, healthsector and teacher-education; development in science and technology sector; and promotion of peace, security and conflict-resolution. Still, he concluded his evaluation with this question: "Despite the numerous gains and advances enumerated, why has our national educational system failed to guarantee the much needed national development?"

The explanation offered for the state of tertiary institutions in Nigeria underscores the importance and urgency of the objectives of this Generally, Conference: pursuit of the delivery of qualityeducation; creation of a climate of transparency and accountability; and institutionalization of integrity in the management of institutions, all towards national development. The pervasive corruption in the wider society notwithstanding, tertiary institutions, especially the university system, has a traditional and special responsibility. For, as I stated over three decades ago concerning the role of the "Academy",

"...ideally, the intellectual community should be the source of ideas and rational guidance for society; it should play a vital role in shaping policy; and by retaining and maintaining a sense of the true, the right, the just, and the fair, it should be the spirit, the conscience, of the society. And in our particular instance, it should lead the struggle for individual and national emancipation from both internal oppressors and external exploiters in all different aspects of life" (Odekunle, 1980).

In the ending of this "accounting", I must confess that I do not remember ever delivering a Lecture/ Address that is not critical; and correspondingly, I do not remember any without provision of remedial suggestions. Thus, with those two considerations as well as the statutory role of the ICPC and other anti-graft agencies (e.g. Code of Conduct Bureau/Tribunal and 
EFCC) in the matter at hand, the next section offers suggestions for the emplacement of transparency, accountability and ethical values in our tertiary institutions.

\section{Towards Emplacement of the Culture of Transparency, Accountability and Ethical Values in Tertiary Institutions}

From the account rendered in the last section, it should be clear that to emplace transparency/ accountability/ethical values optimally in our tertiary institutions, the larger societal context must be enabling for the purpose, first and foremost. Hence, the suggestions being offered here are in two separate, though related, categories: the general, with reference to "all and sundry" in the larger society, and the specific, with particular regard to the situation in our tertiary institutions.

There is the crucial need for our elites and leaders, the "usual" deciders of the ethos/ direction/future of society, to sincerely endeavour to fundamentally alter our current dominant ethos of subordinating "collective" to "individual" interests. For, it is this current ethos that is responsible for the virtual decimation of our "ideal" values, demanding/encouraging/rewarding, as it were, wealth without value-added work; consumption without conscience; position/ office without integrity; business without ethics or morality; politics without principles; even religious worship without manifestation of associated beliefs - and thereby institutionalizing corruption in the society.

However, our experience suggests that our elites and leaders need to be "persuaded", one way or the other. And the preferable way should be the "functionalist" self-correcting modality. Herein lies the urgent need for the anti-corruption agencies (e.g. Code of Conduct Bureau/Tribunal, ICPC, and EFCC) to attend to their statutory mandates with more commitment, seriousness, diligence, and observable-effectiveness than hitherto. In aid of this, I had provided proposals for "reducing the cost of governance" in Nigeria (Odekunle, 2012) and for rationalized "re-positioning" of ICPC for effective function-function-performance (Odekunle, 2012 and 2013:48-55). The outline of the latter is "re-produced" below for the purpose at hand.

First, instead of waiting to receive "reports" before commencing investigation, the Commission should start applying the formula below randomly but "routinely" to both retired and serving political and government office-holders as well as their collaborators in the private sector:

$\mathrm{CG}+\mathrm{CS}+\mathrm{VA}-\mathrm{LI}=\mathrm{PC}[$ for investigation $]$

Where $\quad \mathrm{CG}=$ Consumed Goods

$\mathrm{CS}=$ Consumed Services

$\mathrm{VA} \quad=\quad$ Verified Assets

$\mathrm{LI}=$ Legitimate Income

$\mathrm{PC}=$ Presumed Corruption [for investigation]

Even if the random but "routine" application of this formula captures only one-percent of the population at risk, the deterrent effect will not only significantly curb corruption in the 
present, and henceforth, it will also result in retributive punishment and recovery of funds/ assets that should enhance the image of the Commission as a foremost anti-corruption crusader.

Second, the Commission should ceaselessly pursue those known to have committed large-scale corruption in the past. The "successful" pursuit of even only a "sample" of such offenders [via actual prosecution or "productive" dialogue] would serve not only as general and specific deterrence but will also assist in the reversal of the current trend of the "criminalization" of the state and its apparatuses as well as the culture of impunity. And the Commission should spread this effort, evenly and transparently, across the geo-political zones/political parties/tiers of government, and to the publicized knowledge and/or perception of the generality of the population.

Third, in virtually every prosecution of cases of corruption, the Commission should endeavour to locate the trial in the offender's "place of origin" or known domicile. For the class of people who are more opportuned and/or disposed to perpetrate corruption, the risk of public shame/disgrace and the associated decline in social status for them and their families is a serious deterrent.

Fourth, the Commission should engage "persuasive" dialogue with the "establishment" of the legal, accounting/auditing, and banking professions for these and their ranks to be brought on board to "cooperate" with the Commission in the crusade against corruption. For, as things stand today, they employ the mandates and technicalities of their professions to "collaborate" with offenders before/ during/after commission of the offence - for appreciable share of the proceeds of corruption, often disguised as professional fees.

Fifth, the Commission should start employing more innovative and effective techniques in countering corruption. As example, the use of massively pasted posters, in each Local Government Area [LGA] on every occasion of fund disbursement from the Federation Account on the amount disbursed and the projects approved for execution with such funds [roads, clinics, school-rooms, boreholes, etc] in order to encourage the direct participation of the local population in the anti-corruption fight. Besides, ACTU should be re-designed to report directly to ICPC - for obvious reasons.

Sixth, the Commission should intensify its social mobilization of the general public against corruption with "messages" whose contents are direct, simple, and focused. Using formal [e.g. schools and working-places] and informal [e.g markets and town-meetings] fora, the public should be enlightened as to the "meaning" of corruption in terms of its adverse effects on the provision of roads, light, water, health facilities, education, agricultural subsidies, etc. This also means that the anti-corruption efforts must involve, more than hitherto, the lowest/local level of government/society from where crowds emerge to "chant" support for accused "executive robbers" undergoing trial.

Seventh, the Commission's research department should ensure systematic continuous research into the structure and processes of corruption, conduct annual corruption victimization surveys, as well as periodic evaluation of the effectiveness/efficiency of the 
efforts of the Commission. The inputs therefrom could only enhance its functioning and performance.

Even though the society-wide suggestions would apply to the situation in the tertiary institutions, they cannot sufficiently cover certain peculiarities therein. By their nature, purpose and centrality to national development, the requirements for transparency/accountability/ ethics go beyond the narrow understanding of these terms. For instance, with respect to accountability, the "minimalist" conception only requires that an accountable individual or institution shows that public money has been used for the purposes intended and has not been misappropriated. The optimalist conception however goes beyond that to include adequacy of required in-put of funds/resources and recipient-institution's "returns" on the achievement of the public-good/service entailed (CHE, 2006: 15-17; CHE, 2008:7576). Translated to our case, it implies that accountability would include the adequacy of allocated resources, how they are utilized and managed, as well as the extent of the achievement of the developmental goals of the institutions.

For our tertiary institutions therefore, the following specific suggestions are offered to enhance efficiency/effectiveness of their governance as well as their manifestation of desirable ethical values: Governments/proprietors of tertiary institutions should provide them with rationalized/adequate funding determined by the "resource-based model" of financing (NUC, 2011:68), year-in-year-out.

- $\quad$ Budgeted and approved funds should be released to the institutions as and when due.

- Government should input adequate funding, human material resources to upgrade the quality of prospective entrants into tertiary institutions

- Government's should demand/extract accountability from the institutions with regard to the "quality" of their products/graduates and their "public-good" social responsibility.

- $\quad$ ICPC should periodically execute the provisions of Section $6 \mathrm{~b}, \mathrm{c}, \mathrm{d}$ and e of its statute (ICPC,200:15 16) with respect to tertiary institutions i.e. examine, review, and enforce corruption-prone areas of the institutions and educate/enlighten staff and students therein about corruption to foster their support.

Appointment of Governing Councils of institutions should be guided by the interest and focus of the institutions rather than by the demands of political patronage. Without "interfering" with acceptable level of institutional autonomy, the process for the appointment of Chief Executives of the institutions should be reviewed and tightened to ensure, in each case, the emergence of leaders with leadership integrity who can/will ensure the "radiation" of transparency/accountability/ethical values to other principal officers as well as the staff and students at large. In this regard, the current untoward "intrusion" of populism and indigeneship into the process needs to be extirpated. Just as leadership of a country is critical to its fortunes, so is that of an institution to its performance and ethical atmosphere.

Without detracting from the current dosage of "democracy" in the process of appointing Faculry/ College/School/Departmental Heads, the process should be strictly delimited and 
guided by recognized academic qualifications and hierarchy. There should be a balance between democracy and propriety.

The administration and execution of admission and examination exercises should be deliberately "oversighted" (internally and externally) than hitherto and discovered fraud and malpractices should be certainly and promptly sanctioned - to the knowledge all and sundry in the institution. Here, "whistle-blowing" should be canvassed and encouraged. Without tampering with the "independence" of staff and students unions, members should be encouraged to report observed election and financial malpractices of union-officials to relevant internal and external authorities.

\section{Summary and Concluding Remarks}

In this Address, I have emphasized the importance of tertiary education to national development; briefly described/assessed the state of our tertiary institutions; accounted for their below-par performance of their substantive role in our development; and offered remedial suggestions to reverse the trend and enhance the development-productivity via emplacement of transparency, accountability, and ethical values into their surrounding environment and internal functioning.

I am persuaded that if the offered suggestions were sincerely implemented our tertiary institutions would perform effectively, efficiently, and deliver optimally on their role in our desired national and sustainable development. However, I need to state that I am equally persuaded that the institutions' larger social environment must equally, if not first and foremost, be conducive and enabling since an apple tree cannot produce orange fruits, the genius and machinations of the plant-scientist notwithstanding.

\section{References}

Abangma, J.A. 2001 Education for All Nigerians for Sustainable Development of the Country: Challenges and Prospects, Review of Nigerian Political Economy, Vol. 1. No.1, Jan-June, 127148.

CHE 2006 External (And Internal) Tensions? Conceptualizing Public Accountability in South African Higher Education, CHEHEIAAT, No. 2, December.

CHE (2008)Academic Freedom, Institutional Autonomy and Public Accountability in South African Higher Education, CHE HEIAAT, No. 5 August.

FME (2009) Roadmapforthe Nigerian Education Sector, Federal Ministry of Education, Abuja. ICPC (2000) The Corrupt Practices and Other Related Offences Act 2000, ICPC, Abuja.

Mkpa, A.M. and Gurin, R.A. (2011) The Nigerian Education System and National Development,InMaduagwo,M.D. etal.,(201 led) Nigeria's 50 Years of Nation Building: Stock Taking and Looking Ahead, NIPSS, Kuru, 335-371. 
NUC (2011) Report of a Study on Sustainable Financing of Higher Education in Nigeria, National Universities Commission, Abuja.

Obafemi, O. (2011) Qualitative Tertiary Education in a Knowledge-Based Democratic Culture, In Maduagwo et. Al., (2011) op.cit.

Odekunle, F. Pitfalls of the Academy in Nigeria, In the ABU Sociologist, Department of Sociology, ABU, Zaria.

Odekunle, F. (1983) Corruption in Development, Ibadan University Press.

Odekunle, F. (2008) Effects of Corruption on National Development, Invited Lecture to the Sensitization Prorgamme Against Corruption, Office of the SGF, Conference Hall, Federal Secretariat, Abuja, January.

Odekunle, F. (2012a) Repositioning the ICPC for Effective Performance: Statutory Framework, Staffing, Modus Operandi, and Acknowledgement of Limitation, Retreat on Repositioning thelCPC as a Foremost Agency in the Anti-Corruption Crusade,

ICPC, Ibom Le Meridien Golf Resort, Uyo, May 2-5. Also in Journal of Anti-Corruption Studies, Vol. 1, No. 1, Jan-June.

Odekunle, F. (2012b) Reducing Cost of Governance in Nigeria: The Corruption Factor and the Constitution, Lead Presentation at the 2012 Professor Ben Nwabueze Constitutional Law Public Lecture Series, Institute for Governance Research and Leadership Technology, Abuja, August 25.

Odekunle, F. (2012c) National Security and Education in Nigeria: An Overview Keynote address to the $27^{\text {h }}$ Conference of the Association of Vice-Chancellors of Nigerian Universities, Nasarawa State University, Keffi, September 24.

\section{Appendix: Supportive" Statistics on the State of Tertiary Institutions in Nigeria}

\section{Low ranking of Nigeria's Universities in the World}

- $\quad$ None among the first 5,000.

- In the world, highest-ranked Nigerian Universities were Obafemi Awolowo University (OAU) (5834"'), University of Ibadan (UI) $\left(6809^{\text {th }}\right)$, University of Benin (Uniben) (7318 $\left.8^{\text {th }}\right)$; and University 